\title{
Inquiry and Reflection of the Inheritance and Reference of National Vocal Music Art
}

\author{
Guangtan Qi \\ School of Music \\ Baicheng Normal University \\ Baicheng, China
}

\begin{abstract}
In the study of the inheritance of the Holin-Chor vocal music art in the west of Jilin province, it is found that in the new development period, the inheritance and reference of national vocal music have new opportunities. In the environment of pursuing the development of cultural and artistic diversity, national vocal music art with unique charm can actively enter the social environment, and accelerate the development of national vocal music art with the communication and expression of modern education, to promote the comprehensive development of cultural and artistic undertakings.
\end{abstract}

Keywords—national vocal music; Holin-Chor; inheritance; innovation

\section{INTRODUCTION}

In the context of multiculturalism, social demand and artistic pursuit are unified in the pursuit of diversity, which provides new opportunity for the inheritance and development of national vocal music art, so that folk vocal art can re-show their own artistic charm and get more vigorous life vitality to integrate into the modern art culture system, effectively enrich the kind of modern art, and constantly promote the comprehensive development of cultural and artistic undertakings.

\section{INHERITANCE AND REFERENCE OF NATIONAL VOCAL MUSIC ART}

The inheritance and reference of the national vocal music art is essentially the rejuvenation of the artistic vitality, so that national vocal music art can adapt to the modern social environment, and fully show its artistic charm to win more identity from people, so as to achieve the development of modern society.

In the practical investigation of Holin-Chor vocal music art in west Jilin, it is found that the inheritance and reference of this art still remain in the initial stage. In addition to the small inheritance in the Mongolian aggregated area, the overall performance in other areas is not ideal. Although the governments at all levels and related art institutions took effective supportive activities, they did not achieve the ideal results. The overall inheritance and development is still in a relatively slow initial stage, and the inheritance and reference of "Holin-Chor" vocal music still have misunderstanding in cognition, form, and mode and so on, and still adopt the traditional art inheritance method. They pay attention to the protection of art, but has not achieved great success in the innovation and development of art.

\section{THE INQUIRY OF INHERITANCE AND REFERENCE OF NATIONAL VOCAL MUSIC ART}

\section{A. False Opening up and the Pursuit of Solidified Inheritance}

At the present stage, the inheritance and reference of national vocal music art emphasize the specific inheritance of specific people, making the pursuit of art fall into a kind of solidified state, which has high demand for relevant factors and limits the comprehensive development of "HolinChor" vocal music art. In the inheritance process of "HolinChor", clear lines are made strictly in the crowd. They require that it can only be inherited by specific group or people, which limits the scope of inheritance of "HolinChor" vocal music art. In fact, due to the relatively high demand for the successor, in the inheritance process of "Holin-Chor" vocal music art, there is the phenomenon of the lack of successor and connection between generations. The so-called no successor means that in the process of inheritance, due to the difficulty in exploration of market value and social value of "Holin-Chor" vocal music art, the descendants of the inheritors do not want to be engage in related art research and art work. Disconnection in the inheritance is due to the emergence of extreme inheritance. That is the artistic experience and artistic knowledge of inheritors cannot be effectively inherited, resulting in the serious missing of a lot of valuable vocal music techniques of "Holin-Chor".

The inheritance of "Holin-Chor" vocal music art should be carried out in specific areas in Inner Mongolia and the surrounding areas, including Inner Mongolia, Xinjiang, Heilongjiang, Jilin, and Liaoning and so on. Even in other parts of the Mongolian gathering place, there is no effective inheritance. The regional limitation has seriously restricted the speed and scope of development of "Holin-Chor" vocal music art, so that the foundation of its development becomes very weak and cannot get recognition from more people.

In addition, in the practical communication process, "Holin-Chor" vocal music art have strict requirments on the 
form and mode of communication. In addition to specific ethnic activities and national rituals, it rarely appears in other activities, which also limit the socialization of "Holin-Chor" vocal music art to a certain extent. This is not conducive to the comprehensive development of this art form and buries a lot of hidden dangers for its future development.

\section{B. Large Outlook, Falling into Isolated Development}

In the research process of the modern development of "Holin-Chor" vocal music art, it is found that the excessive pursuit of macro protection leads the manifestation of this vocal music art to break away from the social environment, and even the obvious deification phenomenon, makes the inheritance and development of "Holin-Chor" vocal music art fall into an unprecedented dilemma.

"Holin-Chor" vocal music art obtain the title of National Intangible Cultural Heritage based on its unique national character and artistry. Driven by governments at all levels and related art institutions, "Holin-Chor" vocal music art constantly won a variety of honors. It is no longer a traditional national vocal music art, but an "idol" of national art. However, this high degree of attention and protection eventually lead "Holin-Chor" art to fall into an isolated situation. Because "Holin-Chor" vocal music art has received too much attention, and is given excessive expectations, it is shaped to be seperated from the basic vocal music art and lost their own development vitality, becoming the status of god made of mud in the temple of art.

\section{Empty Prosperity and Innovation Separated from the Foundation}

The research on "Holin-Chor" vocal music art has strong impact, which has been attached great importance by a lot of art institutions and cultural institutions and frequently appear in the field of art research in colleges and universities. Especially in the art research in Inner Mongolia and the surrounding areas, researches on "Holin-Chor" vocal music are very rich in content. In recent years, a large number of related research materials have emerged, showing a very vigorous prosperity. However, the prosperity of this theoretical study cannot bring about the real prosperity of "Holin-Chor" vocal music art. In the areas where "HolinChor" vocal music art develops relatively fast including Jilin, Inner Mongolia, Heilongjiang, and Liaoning and so on, the influence of "Holin-Chor" vocal music art in folk is still relatively low, since many Mongolians do not know the current situation of inheritance of "Holin-Chor" vocal music art and a large number of new works have not emerged.

The prosperity of theory and the weakness in actual development form sharp contrast, indicating that currently, in addition to the problems in inheritance and reference of "Holin-Chor" vocal music art, it has broken away from the substantive nature of art, so it can't take root among people. This art form, which is divorced from the masses, is likely to face serious development dilemmas and even lose the vitality of development.

Although the prosperity of theoretical study play a certain role of promoting the development of this art form, its vigorous development in modern society still rely on its original innovating forces, so that it can get the strong support from social groups and continue to emerge more new works. Only in this way can it ensure that enterprises have vigorous vitality in order to achieve greater progress in the development.

\section{REFLECTION ON THE "INHERITANCE AND REFERENCE" OF NATIONAL VOCAL MUSIC ART}

\section{A. Cultivate the Strength of Inheritance}

The inheritance and reference of the national vocal music should rely on the activities among the inheritors. Therefore, in the practical work, the cultivation of inheritors should be emphasized to fundamentally consolidate the basic strength of artistic inheritance. In the process of cultivating inheritors, we can start from the three angles of inheritors, form and activity, to realize the effective consolidation of the foundation of inheritance and lay a firm foundation for its future development.

In the aspect of inheritor, we can learn from the modern art training methods, to put aside the restrictions on the requirements for people and ethnic groups and introduce more fresh blood through the in-depth cooperation with relevant art institutions, performance agencies, and educational institutions, etc., so that more people can access the "Holin-Chor" art to learn related knowledge, so as to strengthen the inheriting team. As long as we can get support from more inheritors, it can be ensured that in the development process, more outstanding inheritors continue to emerge, which constantly promotes the all-round development of "Holin-Chor" vocal music art.

In the form, we should introduce a new form of modern inheritance by learning from the innovative form of Internet education, and introduce the Internet teaching, mobile teaching and multimedia teaching, etc. into the inheriting work of "Holin-Chor" vocal music. Besides, we can spread the core inheriting knowledge including vocal music techniques, vocal music culture, and vocal music skills to a wide area through a more modern way, so that more people can learn it through a flexible way to master more knowledge and thus speed up the comprehensive development of "Holin-Chor" vocal music art.

In terms of activities, "Holin-Chor" should be effectively integrated with various ethnic activities, cultural activities and artistic activities, so that it can show its unique charm in more activities to get the recognition of more people in the activities and then achieve its comprehensive development in modern society.

\section{B. Integrate into the Social Environment}

The modernized development of "Holin-Chor" vocal music art must be integrated into the social environment and actively discover new demands of the society, so as to find more inspiration for its own innovation and form more innovative works that can comprehensively and truly reflect current social status. Integration of national vocal music art 
into the modern social environment should mainly be carried out in the following two aspects.

First, integrating into the social environment is to establish a close contact with the social environment, use the national vocal art form to reflect the social practice, and conform to the development demand of social practice to contribute more power for the development of social and cultural undertakings. The development of national vocal music in modern society should not be separated from social practice. We should not blindly emphasize the respect and protection of traditional art, but integrate into the modern society with an open mind to encourage the innovative development of national vocal music and insist on creating a new way of development. National vocal art should take the initiative to fit all kinds of new forms, to encourage people to innovate the vocal music art. We can give great support to the innovation activities of vocal music with strong performance effect to make it always maintain a strong vitality in the development of modern society.

Second, to integrate into the social environment, it is necessary to inclusively accept the performance of social development of national vocal music rather than blindly seek refinement and perfection. In the process of national vocal art integrating into the social environment, a large number of vocal music works will inevitably be produced, which have many forms and mixed artistic levels. In the face of this situation, we should not blindly seek refinement and perfection, but praise some quality works and suppress the innovative products that have defects in terms of performance. Only by accepting various attempts of integrating national vocal art into the social environment with an attitude of absorbing anything and everything uncritically can we ensure that the creative enthusiasm of innovators or team can become stronger continuously to form the modern soil that is conducive to the development of national vocal music art, which can ensure it to get a sufficient source of power sustainably in future development, successfully integrate into the modern development environment and become a qualified contributor in modern cultural and artistic system.

\section{Return to the Origin of Innovation}

Both "Holin-Chor" vocal music art and other national vocal music art must return to the origin of innovation in the process of comprehensive development of modern society, and truly strengthen the innovative genes from the source, so that it has sufficient innovation strength and rising innovative enthusiasm to truly become an art form with independent influence and appeal, which requires the national vocal music art explore the source of art constantly in the process of modernization to find the essential that really promote the development of national vocal music art and achieve its development and breakthrough by fully make use of diversified development opportunities in modern social environment.

First of all, national vocal music art should return to the people to become the vocal music art form loved by national masses and even social masses. In the development track of the "Holin-Chor" vocal music art, it can be found that the reason why this art form can be popular in Russia and Mongolia and other places is that it gets the strong support from the people in the region and obtains adequate folk power, so that "Holin-Chor" vocal music art can maintain vigorous innovative enthusiasm, and new excellent works continue to emerge in the process of sustainable development. Therefore, in the process of modernized development of "Holin-Chor" vocal music art and related national vocal music in China, we must return to the folk to get people's approval, dig out more talents, materials and works from the folk and comprehensive display these outstanding results with modern channels of communication to get more recognition.

Second, national vocal art should return to life by starting from the life to make in-depth interpretation of life style, life philosophy and attitude of life, find the trait of modern life fit for the style of "Holin-Chor" vocal music art, and take this trait as the core to transform the national vocal art into a typed art form, which can meet the needs of vocal music art of specific crowd, so as to obtain wider attention.

In the international development of "Holin-Chor" vocal music art, it can be seen that the unique natural charm of "Holin-Chor" vocal music art win wide social concern, and this unique natural charm can form an effective complementation with the current urban living environment, which is an important artistic form that effectively relief the mental stress of people in modern city and guide them to return to nature and enjoy the charm of nature. Therefore, only by finding the pointcut in the philosophy, attitude, and way of life in the developing process can we ensure that national vocal music art get into the social environment and obtain the recognition from more people. Only returning to such source innovation can we make national vocal music art become the world's vocal music art.

Finally, national vocal music art should return to culture to create a new artistic image with the unique cultural charm, to win more people's attention. "Holin-Chor" vocal music art as the important carrier of Mongolian traditional culture, its unique Mongolian characteristic is the most valuable core characteristic. In the process of communication, it can not only get the attention of the Mongolian people, but also attract more attention and focus from social groups. Therefore, in the process of innovative development of "Holin-Chor" vocal music art, attention should be paid to the innovation of culture. We should use the unique cultural characteristics of Mongolian to show the modern life, care about current change in social environment, and integrate the unique cultural spirit of Mongolian into the artistic creation to form more innovative works and comprehensively display the modernized development results of Mongolian culture to win more people's attention.

\section{CONCLUSION}

The inheritance and reference of national vocal music is essentially making national art return to modern society and become an important part of the modern cultural art system to fully show its unique national charm and evolves into the 
national art with world influence. In this process, national vocal music art needs to establish a solid inheritance system, form a set of new system conforming to modern social study and research from inheritor, inheritance form, and traditional inheritance activities, so that more people can join in the process of development and inheritance of national vocal music art to consolidate the essential of development of national vocal music art. Second, national vocal art should integrate into the process of social development, allow the various attempts in the integration process and encourage the modernization of national vocal music with a compatible attitude. Finally, national vocal music art should return to the origin of innovation, find the source of innovation that can move more people from the perspective of returning to the folk, returning to life and returning to the culture, to carry out effective innovation, accelerate the modernized development of national vocal music culture, and influence more people in modern social life to get the recognition from more people.

\section{REFERENCES}

[1] Li Lanlan. Research on Differentiated Teaching and Trait Cultivation of Vocal Music Students of Zang, Qiang and Yi. Sichuan Drama, 2017,(09):168-171(2017-10-09).

[2] Sun Sha. On the Development and Inheritance of Chinese National Vocal Music from the Perspective of "On Singing" in Yuan Dynasty. Northwest University for Nationalities, 2017.

[3] Zhangrong. On the Development and Present Situation of National Vocal Music in China. Art Science and Technology, 2017-04-18.

[4] Yu Lu. A Study on the Inheritance of National Vocal Music from the Perspective of the Original Ecological Folk Songs. Journal of Lvliang Education Institute, 2016,33(03):104-105+109.

[5] Man Xinyu. Absorbing and digesting everything - Inheritance and Exploration of National Vocal Music singing. Liaoning Normal University, 2016.

[6] Li Jun. Inheritance and Excavation of national vocal music to native folk song. Jiangxi Social Sciences, 2015,35(11):252-256

[7] Huang Huang. The Important Role of Fieldwork in the Inheritance of Contemporary National Music - Taking National Vocal Music as an Example. Jiangxi Social Sciences, 2014,34(12):239-242.

[8] Jiang Hongyu. The Inheritance and Development of National Vocal Music art in the Context of Multiculturalism. Liaoning Normal University, 2014.

[9] Li Na, Lv Xiaoshi. The Inheritance and Development of Traditional National Vocal Music art - Combining Vocal Music Teaching in Colleges and Universities. Art Research, 2012,(02):108-109.

[10] Hu Xiaoying. A Study on the Inheritance and Development of minority Vocal Music art in Ethnic Universities and Colleges. Minzu University of China, 2012 